\title{
Role of adiponectin in ovarian follicular development and ovarian reserve
}

\author{
ZAHER MERHI $^{1,2}$, ALI A. BAZZI ${ }^{3}$, ELIZABETH A. BONNEY ${ }^{4}$ and ERKAN BUYUK ${ }^{5}$ \\ ${ }^{1}$ Department of Biochemistry, Albert Einstein College of Medicine, Bronx, NY 10463; \\ ${ }^{2}$ Department of Obstetrics and Gynecology, New York University School of Medicine, New York, NY 10019; \\ ${ }^{3}$ Department of Obstetrics and Gynecology, St. John Hospital and Medical Center, Detroit, MI 48236; \\ ${ }^{4}$ Department of Obstetrics, Gynecology and Reproductive Sciences, University of Vermont College of Medicine, \\ Burlington, VT 05401; ${ }^{5}$ Division of Reproductive Endocrinology and Infertility, Department of Obstetrics \& Gynecology and \\ Women's Health, Montefiore's Institute for Reproductive Medicine and Health, \\ Albert Einstein College of Medicine, Bronx, NY 10461, USA
}

Received November 23, 2018; Accepted April 16, 2019

DOI: $10.3892 /$ br.2019.1213

\begin{abstract}
Adiponectin levels are associated with anti-Müllerian hormone $(\mathrm{AMH})$ and kisspeptin levels in non-ovarian tissues. The objective of the present study was to investigate the association between adiponectin and the genes important for ovarian follicular development and ovarian reserve, specifically $\mathrm{AMH}$ and kisspeptin, and their corresponding receptors. In the first experiment, the mRNA levels of anti-Müllerian hormone $(a m h)$ and its receptor $(A m h r 2)$, as well as those of kisspeptin (Kiss1) and its receptor (Kiss1r), were quantified by reverse transcription-polymerase chain reaction analysis in the ovaries of two groups of mice [adiponectin-knockout (KO) vs. control] that underwent oophorectomy. The second experiment measured follicular phase serum AMH and follicular fluid adiponectin levels in 25 women who underwent controlled ovarian hyperstimulation for in vitro fertilization. Compared with the control mice, adiponectin-KO mice had 6.5 times lower Kiss 1 mRNA levels $(\mathrm{P}=0.009)$ and a tendency for lower ovarian Kiss1r mRNA expression levels $(\mathrm{P}=0.06)$. However, adiponectin-KO mice had significantly higher Amhr 2 mRNA levels $(\mathrm{P}=0.01)$. In all women participants, there was a positive correlation between serum AMH and follicular fluid adiponectin concentrations $(r=0.54, \mathrm{P}=0.006)$. The findings of the present study indicate that adiponectin may play a role in ovarian physiology through its impact on genes crucial for ovarian follicular development and ovarian reserve, such as kisspeptin and AMH. Understanding the role of adiponectin in ovarian function may improve our knowledge
\end{abstract}

Correspondence to: Dr Zaher Merhi, Department of Obstetrics and Gynecology, New York University School of Medicine, 4 Columbus Circle, Fourth Floor, New York, NY 10019, USA E-mail: zom00@hotmail.com

Key words: adiponectin, kisspeptin, anti-Müllerian hormone, obesity of the pathophysiology underlying ovulatory dysfunction in obese women, who usually have low adiponectin levels, and overcome reproductive barriers.

\section{Introduction}

According to recent data, $40 \%$ of the U.S. population over the age of 20 years, and $18 \%$ of children aged 2-19 years, are obese (1). In addition to metabolic disorders, obesity is also associated with reproductive complications, such as menstrual irregularities, subfertility, endometrial hyperplasia and gynecological cancers (2-4). The adipose tissue is an endocrine organ that produces active protein hormones, referred to as adipokines, which are involved in the regulation of energy metabolism, appetite, insulin sensitivity, inflammation, diabetes and metabolic syndrome (5-9). One of the most extensively studied biologically relevant adipokines is adiponectin, which is abundantly produced and secreted by adipose tissue. Furthermore, it has a low expression in obese individuals. Antidiabetic, anti-inflammatory, antiatherogenic and cardioprotective properties of adiponectin are widely known (5-11).

Adiponectin is a $30-\mathrm{kDa}$ glycoprotein hormone produced by mature adipocytes (12). Its mechanism of action occurs mainly in the periphery through binding to two receptors, AdipoR1 and AdipoR2 (12). These receptors are found in reproductive tissues, such as the ovaries, oviduct, endometrium and testis (12). Furthermore, adiponectin modulates gonadotropin release, normal pregnancy, and affects assisted reproduction outcomes (13). Higher adiponectin levels are associated with improved menstrual regularities and better in vitro fertilization (IVF) outcomes (13). In the ovaries, adiponectin plays a key role in oocyte maturation, granulosa cell proliferation and steroid secretion (11,14-16). In animal studies, adiponectin knockout (KO) mice have fewer oocytes, more atretic follicles and prolonged diestrus cycles, indicating that adiponectin plays an important role in folliculogenesis (17). In a retrospective case-controlled study, adiponectin levels were found to be higher among women who conceived after IVF, and were 
positively correlated with the number of oocytes retrieved, regardless of the woman's body mass index (BMI) (18). Similarly, while adiponectin expression is low in human and mouse granulosa cells, its presence is associated with better fertilization rates and better embryonic development $(19,20)$.

Adiponectin is associated with two important genes involved in folliculogenesis: Anti-Müllerian hormone (AMH) and kisspeptin. Interestingly, adiponectin is a regulator of AMH production, possibly via its effects on insulin sensitivity (21). In addition to having low serum and follicular fluid adiponectin levels, obese women also have low AMH levels, which is one of the most reliable markers of ovarian reserve (22). In a previous study, obese women in their late reproductive years were found to have $\sim 65 \%$ lower serum AMH levels compared with normoweight women of the same age $(23,24)$. Through its effects on downstream targets, such as AMP-activated protein kinase (AMPK), adiponectin can mediate the phosphorylation of the transcription factor specificity protein-1 (SP1), which is a regulator of the kisspeptin gene (25). In addition to its regulation of female reproduction at the level of the hypothalamus $(26,27)$, the neuropeptide kisspeptin is expressed in the rat ovary, suggesting a role for kisspeptin in ovarian function $(28,29)$. Obese individuals were found to have lower serum kisspeptin levels compared with normoweight individuals (30). Furthermore, serum kisspeptin levels were found to be negatively correlated with body mass index (BMI) (30), but positively correlated with serum adiponectin (30).

Given this association of adiponectin with AMH and kisspeptin in non-ovarian tissues, the aim of the present study was to assess whether there is any such association in the ovaries.

\section{Materials and methods}

Experimental animals. All protocols were conducted in accordance with the National Institutes of Health guidelines for the care and use of laboratory animals and were approved by the Institutional Animal Care and Use Committee of the University of Vermont College of Medicine. Adiponectin-KO mice, B6.129-Adipoq ${ }^{\mathrm{tm} 1 \mathrm{Chan}} / \mathrm{J}$, were obtained from The Jackson Laboratory (Bar Harbor, ME, USA). A targeting vector was designed to replace exon 2 of the targeted gene with a PGKneo cassette. This construct was electroporated into (129X1/SvJ x 129S1/Sv) F1-derived R1 embryonic stem (ES) cells. Correctly targeted ES cells were injected into blastocysts and chimeric mice were bred with $\mathrm{C} 57 \mathrm{BL} / 6 \mathrm{~J}$ to generate mutant mice. Mutant mice were backcrossed to $\mathrm{C} 57 \mathrm{BL} / 6 \mathrm{~J}$ for at least eight generations. The mice were bred with $\mathrm{C} 57 \mathrm{BL} / 6 \mathrm{~J}$ inbred mice for at least one generation to establish the colony. A 32 single-nucleotide polymorphism (SNP) panel analysis, with 27 markers covering all 19 chromosomes and the $\mathrm{X}$ chromosome, as well as 5 markers that distinguish between the C57BL/6J and C57BL/6N substrains, was performed on the re-derived living colony. This analysis revealed two markers on chromosome 15 and one marker on chromosome 19 that are segregating for 129, suggesting an incomplete backcross. Homozygous mice are viable and fertile, with absence of targeted allele expression confirmed in adipose tissue (mRNA) and plasma (adiponectin protein). While homozygous mice have normal glucose tolerance and insulin resistance, beta-oxidation activity is significantly increased in the muscle and liver. Homozygotes also exhibit endothelial dysfunction (increased leukocyte rolling and leukocyte adhesion), and are more susceptible to myocardial ischemia/reperfusion. According to The Jackson Laboratory, these mice may be useful for studying obesity, diabetes, insulin resistance, metabolism, inflammation, leukocyte-endothelium interactions and colitis.

Adiponectin-KO mice (5 months old; $\mathrm{n}=6$ ) and C57BL/6J wild-type control female mice ( 5 months old; $n=6$ ), were also obtained from The Jackson Laboratory, were housed five to a cage and bred in-house under specific pathogen-free conditions and normal light/dark cycles (14 h light and $10 \mathrm{~h}$ dark cycle), with ad libitum access to standard mouse chow (ProLab ${ }^{\circledR}$ Isopro $^{\circledR}$; chemical composition: 5\% fat, 22\% protein, $59 \%$ carbohydrate, $3.46 \mathrm{kcal} / \mathrm{g}$; PMI Nutrition International, Brentwood, MO, USA) and water. All the mice were sacrificed at 5 months of age by cervical dislocation. At the time of sacrifice, oophorectomy was performed and the ovaries were snap-frozen in liquid nitrogen and stored at $-80^{\circ} \mathrm{C}$ to be used for gene expression analysis.

RNA extraction from mouse ovaries and reverse transcriptionquantitative polymerase chain reaction $(R T-P C R)$ analysis. RT-PCR analysis was performed to quantify the mRNA levels of specific genes that are known to be important in folliculogenesis and their receptors: $a m h$ and its receptor (Amhr2), as well as kisspeptin (Kissl) and its receptor (Kisslr). RNA extraction and RT-qPCR were performed on mouse ovaries that were lysed and homogenized using a homogenizer. RNA was isolated using TRIzol reagent (Invitrogen; Thermo Fisher Scientific, Inc., Carlsbad, CA, USA) and chloroform extraction using RNeasy mini kit (Qiagen Sciences, Inc., Germantown, MD, USA) according to the manufacturer's instructions. RNA analysis quality was assessed by a Nanodrop spectrophotometer and Agilent Bioanalyzer (Agilent Technologies, Inc., Santa Clara, CA, USA). Only samples with a minimum concentration of $10 \mathrm{ng} / \mu 1$, optical density 260:280, and ratio of 1.8-2.0 were used for quantification. The RNA quality was additionally confirmed using RNA electrophoresis. The mRNA expression levels were measured by RT-PCR kinetics using SYBR Green I Chemistry (Roche Diagnostics, Indianapolis, IN, USA), as described elsewhere (31). The primers used were synthesized by Thermo Fisher Scientific (Pittsburgh, PA, USA; Table I). Glyceraldehyde-3-phosphate dehydrogenase (GAPDH) primers were used as a loading control and the levels of mRNA for each gene relative to GAPDH were calculated using the $2^{-\Delta \Delta \mathrm{Cq}}$ method (32).

Subjects and follicular fluid adiponectin levels. A total of 25 women of reproductive age who underwent controlled ovarian hyperstimulation for IVF at Albert Einstein College of Medicine/Montefiore Medical Center (Bronx, NY, USA) between August 2008 and April 2011 were enrolled. Standard IVF procedures were used. Briefly, the participants underwent controlled ovarian hyperstimulation with a combination of gonadotropins (Follistim, Merck \& Co., Inc., Whitehouse Station, NJ, USA; Gonal-F, EMD-Serono, Rockland, MA, USA; Menopur and Bravelle, Ferring, Parsippany, NJ, USA) using either a long agonist (Lupron, AbbVie, North Chicago, 
Table I. Primers used for reverse transcription-polymerase chain reaction analysis.

\begin{tabular}{ll}
\hline Gene & \multicolumn{1}{c}{ Sequence primers (5'-3') } \\
\hline Kiss1 & $\begin{array}{l}\text { Forward: ATGATCTCAATGGCTTCTTGG } \\
\text { Keverse: CCAGGCATTAACGAGTTCCT }\end{array}$ \\
& Forward: GCACATGCAGACAGTTACCAA \\
Amh & Reverse: CACGCAGCACAGTAGGAAAGT \\
& Forward: CGTCACCGCAGCCAGCACA \\
Amhr2 & Reverse: CCCGCAGAGCACGAACCAAG \\
& Forward: CCACAGACCACCACCTTTCC \\
& Reverse: GTCTGCGTCCCAGCAATCTT \\
\hline
\end{tabular}

Amh, anti-Müllerian hormone; Kiss1, kisspeptin.

IL, USA) or antagonist (Ganirelix acetate, Merck \& Co., Inc., or cetrorelix acetate, EMD-Serono) protocol. When $\geq 2$ follicles had reached a diameter of $\geq 17 \mathrm{~mm}$, human chorionic gonadotropin (hCG; Ovidrel, EMD-SeronoMA; or Novarel, Ferring) was administered for oocyte maturation, followed by transvaginal ultrasound-guided oocyte retrieval $34-36 \mathrm{~h}$ later. Women who had known endometriosis or anovulatory infertility, such as polycystic ovary syndrome (PCOS) or hypothalamic amenorrhea, were excluded to minimize the effect of these confounding variables on the results. Women with tubal or male factor infertility were included. BMI was calculated using the following formula: Weight $(\mathrm{kg}) / \mathrm{height}$ $\left(\mathrm{m}^{2}\right)$. For each woman, follicular phase serum AMH was determined by ELISA according to the manufacturer's recommendations; the intra- and inter-assay coefficients of variation were $<15 \%$. Following controlled ovarian hyperstimulation and at the time of oocyte retrieval, follicular fluid was collected for the measurement of adiponectin levels from the first aspirate of the large follicle (>14 mm) to prevent any blood contamination. Adiponectin protein levels were measured by human ELISA kits according to the manufacturer's protocol (Quantakine kit; R\&D Systems, Inc., Minneapolis, MN, USA); the intra- and inter-assay coefficients of variation were $<15 \%$. Each participant reviewed and signed an informed consent document. The study was approved by the Institutional Review Board of Albert Einstein College of Medicine of Yeshiva University and Montefiore Medical Center (approval no. 04-08-199E).

Statistical analysis. Data are expressed as mean \pm standard error of the mean (SEM). The RT-PCR results are expressed as relative number of copies \pm SEM. As the data were not normally distributed, the Mann-Whitney U test was used for comparison of genes between wild-type mice and adiponectin-KO mice. Spearman's correlation analysis was used to evaluate the association between serum AMH and follicular fluid adiponectin levels among the participants. All statistical procedures were run on STATA software (StataCorp LP, College Station, TX, USA) and GraphPad Prism 7 (GraphPad Software, Inc., La Jolla, CA, USA). A P-value $\leq 0.05$ was considered to indicate statistically significant differences.

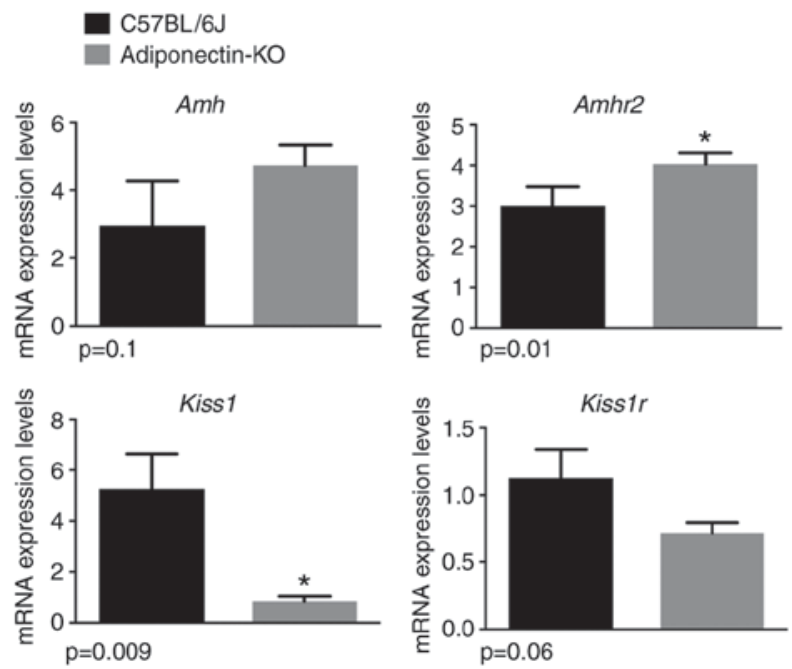

Figure 1. Ovarian Kiss1, Kiss1r, amh and Amhr2 mRNA expression levels in C57BL/6J wild-type control $(\mathrm{n}=6)$ and adiponectin knockout $(\mathrm{KO})$ female mice $(n=6)$. All mice were sacrificed at 5 months of age by cervical dislocation, followed by oophorectomy for reverse transcription-polymerase chain reaction analysis. Compared with control mice, adiponectin $\mathrm{KO}$ mice exhibited significantly lower ovarian Kiss 1 mRNA expression levels, but significantly higher Amhr2 mRNA expression levels. Mann-Whitney's U-test was performed. ${ }^{*} \mathrm{P}<0.05$. Amh, anti-Müllerian hormone; Kiss 1, kisspeptin.

\section{Results}

Effect of adiponectin knockout on Kiss1, Kisslr, amh and Amhr 2 mRNA in mouse ovaries. Adiponectin-KO mice ( $\mathrm{n}=6$ ) on normal chow diet had similar weights compared with wild-type control mice $(n=6)$ on normal chow diet $(P>0.05)$. Compared with control mice, adiponectin-KO mice had 6.5 times lower ovarian Kiss1 mRNA levels $(\mathrm{P}=0.009)$ and the tendency for lower ovarian Kisslr mRNA expression levels ( $\mathrm{P}=0.06$; Fig. 1). By contrast, adiponectin-KO mice had significantly higher Amhr2 mRNA expression levels $(\mathrm{P}=0.01)$ compared with control mice (Fig. 1). Both adiponectin-KO and control mice had similar amh mRNA expression levels ( $\mathrm{P}=0.1)$.

Correlation between follicular fluid adiponectin and serum $A M H$. The demographics and IVF cycle characteristics of the study participants are summarized in Table II. The age of the participants ranged from 19 to 42 years. In all participants, the mean serum AMH level was $1.2 \pm 0.3 \mathrm{ng} / \mathrm{ml}$ and the mean follicular fluid adiponectin level was 2,256 $\pm 197 \mathrm{ng} / \mathrm{ml}$. There was a positive correlation between serum AMH levels and follicular fluid adiponectin concentration $(\mathrm{r}=0.54, \mathrm{P}=0.006$; Fig. 2). BMI was negatively correlated with follicular fluid adiponectin levels ( $\mathrm{r}=-0.4, \mathrm{P}=0.04$, Table II).

\section{Discussion}

To the best of our knowledge, this descriptive study was the first to evaluate the effect of adiponectin gene knockout on Kissl, Kiss 1 , amh and Amhr2 genes in mouse ovaries. It also assessed the association between serum AMH levels and follicular fluid adiponectin levels in women who underwent IVF. First, the results indicated that adiponectin-KO mice had significantly lower Kiss1 mRNA, but higher Amhr2 mRNA expression 
Table II. Demographics and clinical characteristics of the participants.

\begin{tabular}{lcc}
\hline Characteristics & Mean \pm SEM & Correlation with follicular fluid ad \\
\hline Age (years) & $38.9 \pm 0.9$ & $\mathrm{r}=-0.3, \mathrm{P}=0.1$ \\
Body mass index $\left(\mathrm{kg} / \mathrm{m}^{2}\right)$ & $25.6 \pm 1.1$ & $\mathrm{r}=-0.4, \mathrm{P}=0.04$ \\
Baseline day 3 follicle-stimulating hormone $(\mathrm{mIU} / \mathrm{ml})$ & $9.3 \pm 0.7$ & $\mathrm{r}=-0.3, \mathrm{P}=0.2$ \\
Baseline day 3 estradiol $(\mathrm{pg} / \mathrm{ml})$ & $48.3 \pm 3.6$ & $\mathrm{r}=-0.1, \mathrm{P}=0.5$ \\
Dose of gonadotropin per cycle (USP) & $4,491.0 \pm 339.6$ & $\mathrm{r}=-0.4, \mathrm{P}=0.09$ \\
Peak estradiol following ovarian stimulation $(\mathrm{pg} / \mathrm{ml})$ & $1,916.5 \pm 217.5$ & $\mathrm{r}=0.1, \mathrm{P}=0.5$ \\
Number of oocytes retrieved & $10.0 \pm 1.2$ & $\mathrm{r}=0.2, \mathrm{P}=0.4$ \\
Number of mature oocytes & $7.7 \pm 1.2$ & $\mathrm{r}=0.08, \mathrm{P}=0.7$
\end{tabular}

Spearman's correlation analysis was performed. SEM, standard error of the mean.

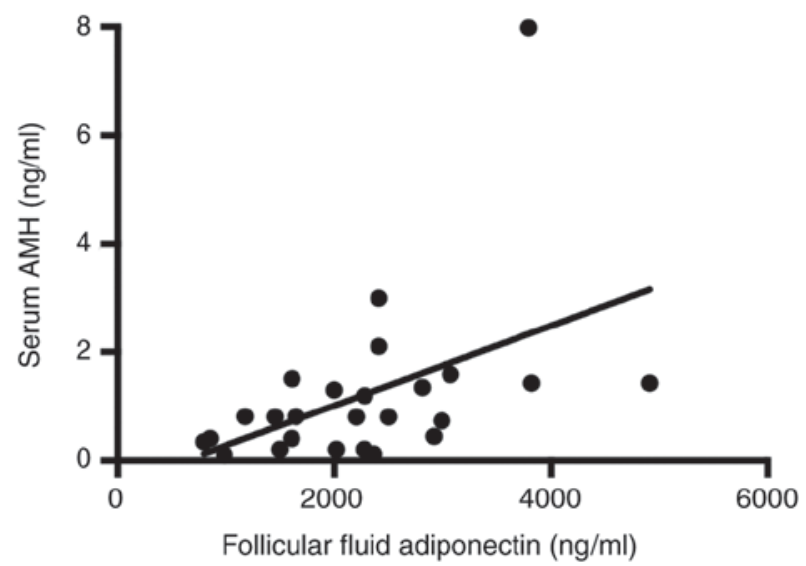

Figure 2. Correlation between follicular fluid adiponectin collected from the first aspirate of the large follicle $(>14 \mathrm{~mm})$ and serum AMH levels in 25 women of reproductive age who underwent in vitro fertilization. Follicular fluid adiponectin levels were positively correlated with serum AMH levels $(r=0.54, \mathrm{P}=0.006)$. AMH, anti-Müllerian hormone.

levels. Adiponectin-KO mice also exhibited a tendency to have lower ovarian Kiss $1 r$ mRNA expression levels and similar amh mRNA levels. The clinical part of this study revealed a positive correlation between serum AMH and follicular fluid adiponectin levels. Furthermore, BMI was found to be negatively correlated with follicular fluid adiponectin levels.

The association between adiponectin and AMH in the serum was previously investigated (33). Nelson et al (33) demonstrated that serum AMH levels in the first trimester of pregnancy were negatively correlated with maternal adiposity, and that AMH levels decline in the 2nd and 3rd trimester of pregnancy as maternal adiposity increases; they also observed that adiponectin was positively correlated with serum AMH (33). Park et al explored the association of insulin resistance and adipokines with AMH levels in women without PCOS (34). Their findings revealed a negative correlation between insulin resistance and AMH levels (34). Furthermore, they also found a positive correlation between serum AMH and adiponectin levels (34). Although their study focused on serum adiponectin levels, their findings are consistent with those of our study, indicating that follicular fluid adiponectin levels are positively correlated with serum AMH levels. In our assessment, adiponectin-KO mice were found to have higher
Amhr2 mRNA expression levels compared with control mice, but similar amh mRNA expression levels. This may be due to adiponectin deficiency-mediated upregulation of $A m h r 2$ that could affect the sensitivity to the action of the AMH protein in the ovary. It is well known that adiponectin is abundantly produced and secreted by adipose tissue, and that its expression and serum levels are lower in obese women (12). In a previous study, obese women in their late reproductive years were found to have $\sim 65 \%$ lower serum AMH levels compared with normoweight women of the same age (23). Thus, a possible explanation for the negative association of AMH and obesity may be adiponectin.

The association between adiponectin and kisspeptin levels has been previously investigated $(35,36)$. Two hormones secreted by adipocytes, leptin and adiponectin, mediate food intake, energy hemostasis and insulin sensitivity (35). Their action involves regulation of gonadotropin-releasing hormone secretion from the hypothalamus, and this is mediated by kisspeptin (35). Specifically, these two hormones modulate Kiss 1 gene expression in GT1-7 neurons in the hypothalamus (25). Furthermore, while leptin decreases insulin sensitivity, adiponectin increases insulin sensitivity (36). In addition to its modulatory effects on the hypothalamus, adiponectin was found to inhibit the transcription of Kissl and Kisslr in islet cells of the pancreas (35). These findings indicate that certain related metabolic disorders, such as obesity and diabetes mellitus, are involved in the regulation of kisspeptin through hormones such as adiponectin. Obese individuals were found to have lower serum kisspeptin levels compared with normoweight individuals (30). Furthermore, there is an inverse association between serum kisspeptin levels and BMI, but a positive correlation between kisspeptin and serum adiponectin levels (30). This correlation was further supported by Zhou et al (37), who demonstrated that high-fat diet-induced obesity caused a marked suppression of ovarian Kiss 1 mRNA levels in mice at postnatal days 42 and 70 compared with normoweight mice on normal chow diet. The association between adiponectin and kisspeptin may be better understood at the biochemical level: Wen et al (25) reported that, through its effects on downstream targets such as AMPK, adiponectin can mediate the phosphorylation of the transcription factor $\mathrm{SP} 1$, which is a regulator of the kisspeptin gene. Our study further confirmed this association between adiponectin and kisspeptin, as it was demonstrated that adiponectin-KO mice 
had significantly lower Kiss1 mRNA levels compared with control mice (Fig. 1). This is opposite to the findings reported by Latif et al (38), who concluded that there was no significant association between kisspeptin and adiponectin in any of the menstrual phases, despite the proven presence of kisspeptin receptors on adipocytes. That study had several limitations, including a small sample size, making it difficult to draw a definitive conclusion (38). Furthermore, due to the minimal fluctuations of kisspeptin during the menstrual cycle, the levels of kisspeptin during this time period may not correlate to the secretion of adiponectin and, thus, may not provide an accurate assessment of the association between kisspeptin and adiponectin (38). Our findings have potential implications in reproduction and may help us to better understand and overcome barriers to reproductive success. Kisspeptin has been shown to affect ovarian follicular development and ovarian reserve. We have demonstrated that older mice had significantly higher Kissl and Kisslr levels in their ovaries compared with younger mice (39). The sensitivity of kisspeptin may be altered by age-related upregulation of KissIr (39). Therefore, a better understanding of the kisspeptinergic system and its mediators, such as adiponectin, may reveal new treatment strategies to overcome reproductive barriers, particularly in obese women, who usually have low levels of adiponectin.

This study had several limitations. When quantifying mRNA expression levels, we used the whole mouse ovary, which includes a number of different components, such as granulosa, theca and stromal cells (39). Previous studies have demonstrated that theca and stromal cells are the major sites of Kiss 1 expression, but another study reported that the granulosa cells are the main site of Kiss1 expression (37). Therefore, future studies should focus on identifying the specific type of cell where the hormone being studied is mainly expressed. Another limitation of this study is that we did not measure serum AMH, a measure of ovarian reserve, in our adiponectin-KO animal model. In this experiment, mRNA expression was used as a determinant of gene expression, but mRNA may not necessarily translate into protein; thus, future mechanistic studies should involve western blotting and immunofluorescence experiments. In the present study, human participants who underwent controlled ovarian hyperstimulation with gonadotropins for IVF treatment were exposed to a combination of hormones that may affect adiponectin levels. Future studies should evaluate ovarian histology and follicular dynamics (e.g., number of primordial follicles) in adiponectin-KO mice, whereas in humans, they should focus on controlling for the number and type(s) of gonadotropins used per cycle for controlled ovarian hyperstimulation. Furthermore, AMH levels were measured in the serum in order to determine a baseline ovarian reserve measure, while adiponectin levels were measured in the follicular fluid in order to assess its ovarian levels.

In conclusion, the present study suggests that adiponectin may play a key role in ovarian physiology through its impact on genes important for ovarian follicular development and ovarian reserve, such as kisspeptin and AMH. Our results support the presence of a possible common denominator and modulator, such as adiponectin, for genes important for reproduction. Further elucidating this association and the underlying biochemical pathways that affect its expression may lead to targeted and specific therapies to improve ovarian health, particularly in obese women who have low systemic adiponectin levels.

\section{Acknowledgements}

Not applicable.

\section{Funding}

The present study was supported by a grant from the American Society for Reproductive Medicine (ASRM) and by a grant from Ferring Pharmaceuticals.

\section{Availability of data and materials}

All the data are available from our clinical patient software upon reasonable request.

\section{Ethics approval and consent to participate}

All protocols were conducted in accordance with the National Institutes of Health guidelines for the care and use of laboratory animals and were approved by the Institutional Animal Care and Use Committee of the University of Vermont College of Medicine. Studies on human participants were approved by the Institutional Review Board of Albert Einstein College of Medicine of Yeshiva University and Montefiore Medical Center (approval no. 04-08-199E). All participants reviewed and signed an informed consent document.

\section{Patient consent for publication}

Not applicable.

\section{Authors' contributions}

$\mathrm{ZM}, \mathrm{EB}$ and EAB participated in the design of the animal and human studies, collected data from participants, and performed the statistical analysis; $\mathrm{AB}$ participated in writing the manuscript and performed the literature search. All the authors have read and approved the final version of this manuscript for publication.

\section{Competing interests}

The authors declare that they have no competing interests.

\section{References}

1. Hales CM, Carroll MD, Fryar CD and Ogden CL: Prevalence of obesity among adults and youth: United States, 2015-2016. NCHS Data Brief: 1-8, 2017.

2. Wang YC, McPherson K, Marsh T, Gortmaker SL and Brown M: Health and economic burden of the projected obesity trends in the USA and the UK. Lancet 378: 815-825, 2011.

3. Tzeng CR, Chang YC, Chang YC, Wang CW, Chen $\mathrm{CH}$ and Hsu MI: Cluster analysis of cardiovascular and metabolic risk factors in women of reproductive age. Fertil Steril 101: 1404-1410, 2014

4. Wei S, Schmidt MD, Dwyer T, Norman RJ and Venn AJ: Obesity and menstrual irregularity: Associations with SHBG, testosterone, and insulin. Obesity (Silver Spring) 17: 1070-1076, 2009. 
5. Wise MR, Jordan V, Lagas A, Showell M, Wong N, Lensen S and Farquhar CM: Obesity and endometrial hyperplasia and cancer in premenopausal women: A systematic review. Am J Obstet Gynecol 214: 689.e1-689.e17, 2016.

6. Massetti GM, Dietz WH and Richardson LC: Excessive weight gain, obesity, and cancer: Opportunities for clinical intervention. JAMA 318: 1975-1976, 2017.

7. Lee B and Shao J: Adiponectin and energy homeostasis. Rev Endocr Metab Disord 15: 149-156, 2014.

8. Arita Y, Kihara S, Ouchi N, Takahashi M, Maeda K, Miyagawa J, Hotta K, Shimomura I, Nakamura T, Miyaoka K, et al: Paradoxical decrease of an adipose-specific protein, adiponectin, in obesity. Biochem Biophys Res Commun 257: 79-83, 1999.

9. Kondo H, Shimomura I, Matsukawa Y, Kumada M, Takahashi M, Matsuda M, Ouchi N, Kihara S, Kawamoto T, Sumitsuji S, et al: Association of adiponectin mutation with type 2 diabetes: A candidate gene for the insulin resistance syndrome. Diabetes 51 2325-2328, 2002.

10. Ohashi K, Ouchi N, Kihara S, Funahashi T, Nakamura T, Sumitsuji S, Kawamoto T, Matsumoto S, Nagaretani H, Kumada M, et al: Adiponectin I164T mutation is associated with the metabolic syndrome and coronary artery disease. J Am Coll Cardiol 43: 1195-1200, 2004.

11. Kadowaki T, Yamauchi T, Kubota N, Hara K, Ueki K and Tobe K: Adiponectin and adiponectin receptors in insulin resistance, diabetes, and the metabolic syndrome. J Clin Invest 116: 1784-1792, 2006.

12. Nigro E, Scudiero O, Ludovica MM, Palmieri A, Mazzarella G, Costagliola C, Bianco A and Daniele A: New insight into adiponectin role in obesity and obesity-related diseases. Biomed Res Int Article 2014: 658913, 2014

13. Michalakis KG and Segars JF: The role of adiponectin in reproduction: From polycystic ovary syndrome to assisted reproduction. Fertil Steril 94: 1949-1957, 2010.

14. Chabrolle C, Tosca L and Dupont J: Regulation of adiponectin and its receptors in rat ovary by human chorionic gonadotrophin treatment and potential involvement of adiponectin in granulosa cell steroidogenesis. Reproduction 133: 719-731, 2007.

15. Ledoux S, Campos DB, Lopes FL, Dobias-Goff M, Palin MF and Murphy BD: Adiponectin induces periovulatory changes in ovarian follicular cells. Endocrinology 147: 5178-5186, 2006.

16. Chabrolle C, Tosca L, Crochet S, Tesseraud S and Dupont J: Expression of adiponectin and its receptors (AdipoR1 and AdipoR2) in chicken ovary: Potential role in ovarian steroidogenesis. Domest Anim Endocrinol 33: 480-487, 2007.

17. Cheng L, Shi H, Jin Y, Li X, Pan J, Lai Y, Lin Y, Jin Y, Roy G, Zhao A and Li F: Adiponectin deficiency leads to female subfertility and ovarian dysfunctions in mice. Endocrinology 157 4875-4887, 2016.

18. Liu YH, Tsai EM, Wu LC, Chen SY, Chang YH, Jong SB and Chan TF: Higher basal adiponectin levels are associated with better ovarian response to gonadotropin stimulation during in vitro fertilization. Gynecol Obstet Invest 60: 167-170, 2005.

19. Richards JS, Liu Z, Kawai T, Tabata K, Watanabe H, Suresh D, Kuo FT, Pisarska MD and Shimada M: Adiponectin and its receptors modulate granulosa cell and cumulus cell functions, fertility, and early embryo development in the mouse and human Fertil Steril 98: 471-479.e1, 2012.

20. Chang HJ, Lee JH, Lee JR, Jee BC, Suh CS and Kim SH: Relationship between follicular fluid adipocytokines and the quality of the oocyte and corresponding embryo development from a single dominant follicle in in vitro fertilization/intracytoplasmic sperm injection cycles. Clin Exp Reprod Med 41: 21-28, 2014.

21. Seifer DB and Maclaughlin DT: Mullerian Inhibiting Substance is an ovarian growth factor of emerging clinical significance. Fertil Steril 88: 539-546, 2007.

22. van Rooij IA, Broekmans FJ, te Velde ER, Fauser BC, Bancsi LF, de Jong FH and Themmen AP: Serum anti-Müllerian hormone levels: A novel measure of ovarian reserve. Hum Reprod 17: 3065-3071, 2002.
23. Freeman EW, Gracia CR, Sammel MD, Lin H, Lim LC and Strauss JF III: Association of anti-mullerian hormone levels with obesity in late reproductive-age women. Fertil Steril 87: 101-106, 2007.

24. Buyuk E, Seifer DB, Illions E, Grazi RV and Lieman H: Elevated body mass index is associated with lower serum anti-mullerian hormone levels in infertile women with diminished ovarian reserve but not with normal ovarian reserve. Fertil Steril 95: 2364-2368, 2011

25. Wen JP, Liu C, Bi WK, Hu YT, Chen Q, Huang H, Liang JX, Li LT, Lin LX and Chen G: Adiponectin inhibits KISS1 gene transcription through AMPK and specificity protein-1 in the hypothalamic GT1-7 neurons. J Endocrinol 214: 177-189, 2012.

26. Hameed S, Jayasena CN and Dhillo WS: Kisspeptin and fertility. J Endocrinol 208: 97-105, 2011

27. de Roux N, Genin E, Carel JC, Matsuda F, Chaussain JL and Milgrom E: Hypogonadotropic hypogonadism due to loss of function of the KiSS1-derived peptide receptor GPR54. Proc Natl Acad Sci USA 100: 10972-10976, 2003.

28. Seminara SB, Messager S, Chatzidaki EE, Thresher RR, Acierno JS Jr, Shagoury JK, Bo-Abbas Y, Kuohung W, Schwinof KM, Hendrick AG, et al: The GPR54 gene as a regulator of puberty. N Engl J Med 349: 1614-1627, 2003.

29. Terao Y, Kumano S, Takatsu Y, Hattori M, Nishimura A, Ohtaki T and Shintani Y: Expression of KiSS-1, a metastasis suppressor gene, in trophoblast giant cells of the rat placenta. Biochim Biophys Acta 1678: 102-110, 2004.

30. Kołodziejski PA, Pruszyńska-Oszmałek E, Korek E, Sassek M, Szczepankiewicz D, Kaczmarek P, Nogowski L, Maćkowiak P, Nowak KW, Krauss H and Strowski MZ: Serum levels of spexin and kisspeptin negatively correlate with obesity and insulin resistance in women. Physiol Res 67: 45-56, 2018.

31. Merhi Z, Buyuk E, Berger DS, Zapantis A, Israel DD, Chua S Jr and Jindal S: Leptin suppresses anti-Mullerian hormone gene expression through the JAK2/STAT3 pathway in luteinized granulosa cells of women undergoing IVF. Hum Reprod 28: 1661-1669, 2013

32. Livak KJ and Schmittgen TD: Analysis of relative gene expression data using real-time quantitative PCR and the 2(-Delta Delta C(T)) method. Methods 25: 402-408, 2001.

33. Nelson SM, Stewart F, Fleming R and Freeman DJ: Longitudinal assessment of antimüllerian hormone during pregnancyrelationship with maternal adiposity, insulin, and adiponectin. Fertil Steril 93: 1356-1358, 2010

34. Park HT, Cho GJ, Ahn KH, Shin JH, Kim YT, Hur JY, Kim SH, Lee KW and Kim T: Association of insulin resistance with anti-Mullerian hormone levels in women without polycystic ovary syndrome (PCOS). Clin Endocrinol (Oxf) 72: 26-31, 2010 .

35. Mahmoodzadeh Sagheb M, Azarpira N and Yaghobi R: The effect of leptin and adiponectin on KiSS-1 and KissR mRNA expression in rat islets of langerhans and CRI-D2 cell line. Int J Endocrinol Metab 12: e15297, 2014.

36. Ahima RS and Lazar MA: Adipokines and the peripheral and neural control of energy balance. Mol Endocrinol 22: 1023-1031, 2008.

37. Zhou Q, Chen H, Yang S, Li Y, Wang B, Chen Y and Wu X: High-fat diet decreases the expression of Kiss1 mRNA and kisspeptin in the ovary, and increases ovulatory dysfunction in postpubertal female rats. Reprod Biol Endocrinol 12: 127, 2014.

38. Latif R, Rafique N, Salem AM, AlSheikh MH and Chathoth S: Correlation between circulatory Kisspeptin and Adipokines in normal and over-weight Saudi females during menstrual cycle. Biol Rhythm Res 49: 169-174, 2018

39. Merhi Z, Thornton K, Bonney E, Cipolla MJ, Charron MJ and Buyuk E: Ovarian kisspeptin expression is related to age and to monocyte chemoattractant protein-1. J Assist Reprod Genet 33: 535-543, 2016. 